\title{
Evaluation of craniofacial morphology in short-statured children: growth hormone deficiency versus idiopathic short stature
}

\author{
Ki Bong Kim ${ }^{1, *}$, Eun-Kyong Kim ${ }^{2, *}$, Kyung Mi Jang ${ }^{3}$, Min Seon Kim ${ }^{4}$, Eun Young Park ${ }^{1}$ \\ ${ }^{1}$ Department of Dentistry, Yeungnam University College of Medicine, Daegu, Korea \\ ${ }^{2}$ Department of Dental Hygiene, College of Science and Technology, Kyungpook National University, Sangju, Korea \\ ${ }^{3}$ Department of Pediatrics, Yeungnam University College of Medicine, Daegu, Korea \\ ${ }^{4}$ Department of Dentistry, Yeungnam University Hospital, Daegu, Korea
}

Received: May 7, 2020

Revised: June 5, 2020

Accepted: June 11, 2020

Corresponding author:

Eun Young Park

Department of Dentistry, Yeungnam

University College of Medicine, 170

Hyeonchung-ro, Nam-gu, Daegu

42415, Korea

Tel: +82-53-620-3282

Fax: +82-53-629-1772

E-mail: acidic@yu.ac.kr

*These authors contributed equally to this work.
Background: Short stature is defined as a height below the 3rd percentile or more than two standard deviations below the mean for a given age, sex, and population. There have been inconsistent results regarding craniofacial morphology in short-statured children. This study aimed to analyze the differences between short-statured children with growth hormone deficiency, idiopathic short-statured children, and normal children.

Methods: Thirty-one short-statured children with growth hormone deficiency, 32 idiopathic short-statured children, and 32 healthy children were enrolled in this study. The measurements of their craniofacial structures from lateral cephalograms were evaluated.

Results: There were statistically significant differences among the three groups seven variables (anterior cranial base length, posterior cranial base length, total cranial base length, upper posterior facial height, posterior total facial height, mandibular ramus length, and overall mandibular length) in the linear measurement and five variables (saddle angle, gonial angle, mandibular plane angle, position of mandible, and maxilla versus mandible) in the angular measurement. Conclusion: Compared to the control group, many linear and angular measurements of the craniofacial structures were significantly different in the two short-statured groups $(p<0.05)$. Treatment plans by orthodontists should include these craniofacial structure characteristics.

Keywords: Child; Growth; Mandible; Maxilla; Orthodontists

\section{Introduction}

Heightism is a newly invented word that combines "height" and "ism", and it refers to the privilege enjoyed by those with tall stature. Nicholas Herpin, a French sociologist, says in his book 'Le Pouboir des grands' that a man's big height works in favor of his status, salary, love, marriage, and many other factors, and his height is a power [1].
In Korea, parents with growing children are often concerned about their child's final height. In a survey conducted by the Korean Society of Pediatric Endocrinology, found that Korean parents considered the ideal final height of their children to be over $175 \mathrm{~cm}$ and less than $180 \mathrm{~cm}(46.6 \%, 178 / 382$ persons), with over $180 \mathrm{~cm}$ (42.7\%, 163/382 persons) for males, and over $165 \mathrm{~cm}$ to less than $170 \mathrm{~cm}$ (54.6\%, 532/975 persons), followed by $160 \mathrm{~cm}$ to less than $165 \mathrm{~cm}$ (36.5\%, 356/975 persons) for females. This exceeds

Copyright (C) 2021 Yeungnam University College of Medicine

This is an Open Access article distributed under the terms of the Creative Commons Attribution Non-Commercial License (http://creativecommons.org/licenses/by-nc/4.0/) which permits unrestricted non-commercial use, distribution, and reproduction in any medium, provided the original work is properly cited. 
the average height of 20 to 29 -year-old males and females in Korea, of $174.1 \mathrm{~cm}$ and $161.6 \mathrm{~cm}$, respectively. In addition, parents said they were concerned that a short stature would be unfavorable to their child's social life and interpersonal relationships [2].

Short stature is defined as a height below the 3rd percentile or more than two standard deviations below the mean for a given age, sex, and population [3]. The causes of short stature can be divided into three broad categories: chronic disease (including undernutrition, genetic disorders), familial short stature, and constitutional delay of growth and development. Most children with short stature have normal variants such as familial short stature, constitutional delay of growth and puberty, or idiopathic short stature. Approximately $5 \%$ of children referred for evaluation of short stature have an identifiable pathologic cause. The most common etiologies are growth hormone deficiency, hypothyroidism, celiac disease, and Turner syndrome. Other causes include renal, hepatic, gastrointestinal diseases, and other genetic syndromes such as Noonan syndrome and Leri Weill syndrome [4-9].

In past studies of craniofacial bones for short-statured children, inconsistent results regarding the growth of the cranial base were reported [10-12]. However, recent literature showed that the dimensions of the craniofacial structures were smaller in short-statured children $[13,14]$.

There has not been a clear explanation of the craniofacial morphology by cause in short-statured children with growth disorders. Many issues need to be considered by orthodontists treating short-statured children.

This study aimed to analyze the differences in craniofacial morphology between short-statured children with growth hormone deficiency (SS-HD), idiopathic short-statured children (SS-I), and normal children (NC). These findings could provide basic information for developing orthodontic treatment protocols for short-statured children.

\section{Materials and methods}

\section{Subjects}

This study received approval from the Institutional Review Board of Yeungnam University Hospital (IRB No: 2019-03-007-001). All participants and their parents gave their informed consent.

Children diagnosed with short stature between 2006 and 2012 at the Department of Pediatrics, Yeungnam University Hospital, Daegu, Korea, were eligible for this study. Patients and their parents were asked if measurements of their craniofacial structures could be taken by an orthodontist at the Department of Dentistry, Yeungnam University Hospital. Those who agreed were referred to the Department of Dentistry.

All participants of the case group were classified into two subject groups: 31 SS-HD and 32 SS-I. Paired sampling was used to match the 31 SS-HD subjects with the SS-I subjects in terms of age and sex.

The control group consisted of $32 \mathrm{NC}$ who had visited the dental clinic in Daegu (paired sampling was used to match the 31 SSHD subjects in terms of age and sex). All of them had an Angle's class I malocclusion and arch length discrepancy less than $3 \mathrm{~mm}$.

\section{Methods}

1) Demographic characteristics

Age and sex were provided in the medical records of the short-stat-

Table 1. Twelve cephalometric landmarks

\begin{tabular}{|c|c|c|}
\hline Name & Abbreviation & Description \\
\hline Sella & S & The center of the sella turcica \\
\hline Nasion & $\mathrm{N}$ & The most anterior point of the frontonasal suture \\
\hline Subspinale & A & $\begin{array}{l}\text { The most posterior point on the curvature from the anterior nasal spine to the crest of the maxillary alveo- } \\
\text { lar process }\end{array}$ \\
\hline Supraentale & B & $\begin{array}{l}\text { The most posterior point on the curvature of the mandible between pogonion and the crest of the mandib- } \\
\text { ular alveolar process }\end{array}$ \\
\hline Pogonion & Pog & The most anterior point on the contour of chin \\
\hline Gnathion & Gn & A bony point by bisecting line of angle formed by facial plane and mandibular plane \\
\hline Menton & Me & The most inferior point on the symphyseal outline \\
\hline Gonion & Go & A bony point by bisecting line of angle formed by ramal plane and mandibular plane \\
\hline Articulare & Art & $\begin{array}{l}\text { The point of intersection of the inferior cranial base surface basioccipital and the posterior surface of the } \\
\text { mandibular condyle }\end{array}$ \\
\hline Basion & $\mathrm{Ba}$ & The most inferior posterior point on the anterior margin of the foramen magnum \\
\hline Posterior nasal spine & PNS & The most posteior point on the bony hard palate \\
\hline Anterior nasal spine & ANS & The most anterior point on the maxilla at the level of the palate \\
\hline
\end{tabular}




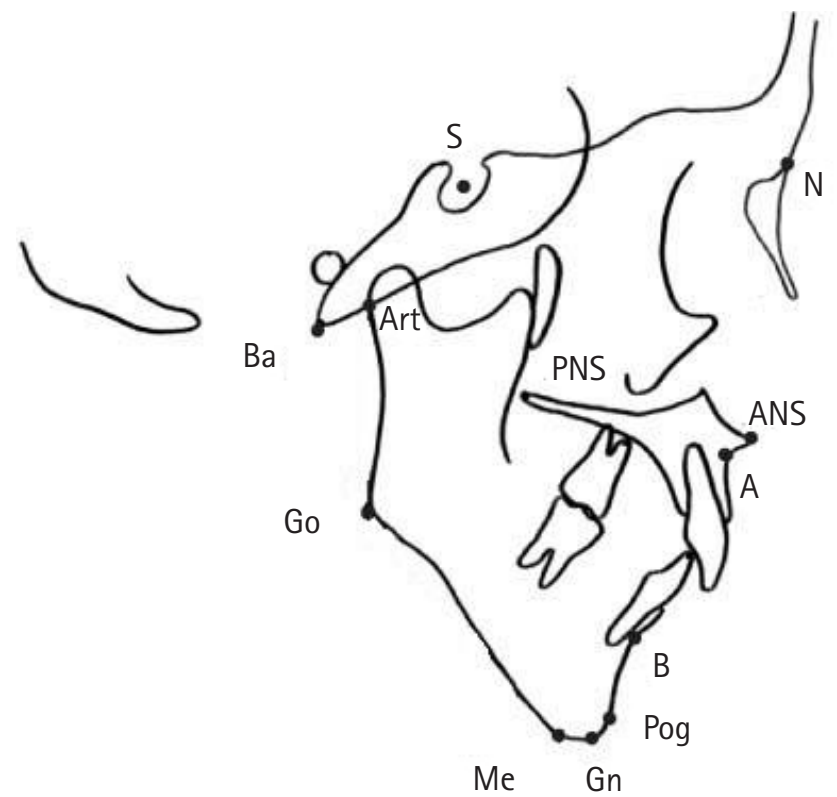

Fig. 1. Cephalometric landmarks. S, sella; $N$, nasion; $B a$, basion; Art, articulare; PNS, posterior nasal spine; ANS, anterior nasal spine; Go, gonion; A, subspinale; $B$, supraentale; Pog, pogonion; Me, menton; Gn, gnathion.

ured subjects and the chart records of the normal subjects.

\section{2) Cephalometric analysis}

In all participants, lateral cephalograms were taken by a single dentist and a single dental hygienist with their teeth in maximum habitual intercuspation with relaxed lips and face positioned with the Camper's plane parallel to the ground. Twelve cephalometric reference points were identified (Table 1, Fig. 1). Then, using these, 12 linear and seven angular cephalometric measurements were taken to evaluate the craniofacial morphology (Table 2) [15].

\section{3) Statistical analysis}

Statistical analysis was performed using IBM SPSS version 19.0 (IBM Corp., Armonk, NY, USA). According to the variables, a frequency analysis and multivariate analysis of variance (ANOVA) with Bonferroni correction were used to compare the characteristics of the groups. A $p$-value of $<0.05$ was considered statistically significant.

\section{Results}

\section{Demographic characteristics of the study subjects}

A total of 95 children participated in this study, and the general and physical characteristics of each group are shown in Table 3 . The number, sex, and age of each group were as follows: 31 SS-HD, 16 males and 15 females, mean age, $10.35 \pm 1.84$ years; 32 SS-I, 16
Table 2. Linear and angular craniofacial measurements

\begin{tabular}{|c|c|c|}
\hline Measurement & Abbreviation & Cephalometric landmark \\
\hline \multicolumn{3}{|l|}{ Linear } \\
\hline Anterior cranial base length ${ }^{\text {a) }}$ & ACB & $\mathrm{N}-\mathrm{S}$ \\
\hline Posterior cranial base length ${ }^{\text {a) }}$ & PCB & S-Ba \\
\hline Total cranial base length & TCB & $\mathrm{N}-\mathrm{Ba}$ \\
\hline Upper anterior facial height ${ }^{\mathrm{a})}$ & UAFH & N-ANS \\
\hline Upper posterior facial height & UPFH & S-PNS \\
\hline Lower anterior facial height ${ }^{\text {a) }}$ & LAFH & ANS-Me \\
\hline Anterior total facial height ${ }^{a)}$ & ATFH & $\mathrm{N}-\mathrm{Me}$ \\
\hline Posterior total facial height & PTFH & S-Go \\
\hline Maxillar length ${ }^{\mathrm{a})}$ & MaxL & ANS-PNS \\
\hline Mandibular ramus length ${ }^{\text {a) }}$ & MandRL & Art-Go \\
\hline Mandibular corpus length ${ }^{\text {a) }}$ & MandCL & Go-Pog \\
\hline Overall mandibular length & OMandL & Art-Pog \\
\hline \multicolumn{3}{|l|}{ Angular } \\
\hline Saddle angle $e^{a)}$ & SA & N-S-Art \\
\hline Gonial angle & $\mathrm{GA}$ & Art-Go-Me \\
\hline Mandibular plane angle ${ }^{a)}$ & MPA & $\mathrm{S}-\mathrm{N}-\mathrm{Go}-\mathrm{Gn}$ \\
\hline Position of maxilla & SNA & S-N-A \\
\hline Position of mandible ${ }^{a)}$ & SNB & S-N-B \\
\hline Maxilla/mandible $e^{a}$ & ANB & $A-N-B$ \\
\hline Posterior position of mandible & PPMand & S-N-Art-Go \\
\hline
\end{tabular}

males and 16 females, mean age, $10.31 \pm 1.82$ years; and $32 \mathrm{NC}, 17$ males and 15 females, mean age, $10.31 \pm 1.82$ years, respectively.

\section{Cephalometric analysis}

Comparison of the linear and angular craniofacial variables among the SS-HD, SS-I, and NC groups are shown in Tables 4 and 5.

Regarding the linear measurements, there were significant differences in seven variables among the SS-HD, SS-I, and NC groups $(p<0.05)$. In the two groups, mandibular ramus length (MandRL) were $36.10 \pm 0.57$ and $37.22 \pm 0.67$, and overall mandibular length (OMandL) were $96.50 \pm 0.79$ and $99.52 \pm 0.75$, respectively. There were all statistically significant $(p<0.05)$. Significant differences between the SS-HD and NC groups were apparent at anterior cranial base length $(\mathrm{ACB})$, posterior cranial base length $(\mathrm{PCB})$, total cranial base length (TCB), upper posterior facial height (UPFH), posterior total facial height (PTFH), MandRL, and mandibular corpus length (MandCL) $(p<0.05)$. Significant differences between the SS-I group and NC group were apparent at ACB, PCB, UPFH, MandRL, and MandCL $(p<0.05)$.

Regarding the angular measurements, there were significant differences in five variables among the SS-HD, SS-I, and NC groups $(p<0.05)$. In the two groups, gonial angle (GA) were $127.39 \pm 0.51$ and $125.38 \pm 0.28$, position of mandible $(\mathrm{SNB})$ were $75.03 \pm 0.42$ 
Table 3. Demographic characteristics of subjects

\begin{tabular}{lcccc}
\hline Variable & \multicolumn{3}{c}{ Group } & Total $(n=95)$ \\
\cline { 2 - 3 } Sex & SS-HD $(n=31)$ & SS-I $(n=32)$ & NC $(n=32)$ & $17(53.1)$ \\
$\quad$ Male & $16(51.6)$ & $16(50.0)$ & $15(46.9)$ & $49(51.6)$ \\
Female & $15(48.4)$ & $16(50.0)$ & $10.31 \pm 1.82$ & $46(48.4)$ \\
Age (yr) & $10.35 \pm 1.84$ & $10.31 \pm 1.82$ & $10.33 \pm 1.81$ \\
\hline
\end{tabular}

Values are presented as number (\%) or mean \pm standard deviation.

SS-HD, short-statured children with growth hormone deficiency; SS-I, idiopathic short-statured children; NC, normal children.

Table 4. Comparison for the linear craniofacial variables among SS-HD, SS-I, and NC groups

\begin{tabular}{|c|c|c|c|c|}
\hline \multirow{2}{*}{ Linear (mm) } & \multicolumn{3}{|c|}{ Group } & \multirow{2}{*}{$p$-value } \\
\hline & SS-HD $(n=31)$ & SS-I $(n=32)$ & $N C(n=32)$ & \\
\hline$\overline{A C B}$ & $64.41 \pm 0.43^{a}$ & $65.09 \pm 0.40^{\mathrm{a}}$ & $67.64 \pm 0.37^{b}$ & $<0.001$ \\
\hline PCB & $44.01 \pm 0.54^{\mathrm{a}}$ & $44.89 \pm 0.37^{a}$ & $46.70 \pm 0.55^{b}$ & $<0.001$ \\
\hline TCB & $99.40 \pm 0.84^{\mathrm{a}}$ & $100.77 \pm 0.62^{\mathrm{ab}}$ & $102.66 \pm 0.64^{b}$ & 0.006 \\
\hline UAFH & $51.71 \pm 0.50$ & $51.97 \pm 0.53$ & $53.31 \pm 0.51$ & 0.065 \\
\hline UPFH & $46.13 \pm 0.28^{\mathrm{a}}$ & $46.31 \pm 0.23^{a}$ & $48.28 \pm 0.41^{b}$ & $<0.001$ \\
\hline LAFH & $64.24 \pm 0.63$ & $64.80 \pm 0.54$ & $64.34 \pm 0.54$ & 0.764 \\
\hline ATFH & $114.65 \pm 0.75$ & $115.41 \pm 0.81$ & $116.33 \pm 0.78$ & 0.318 \\
\hline PTFH & $66.74 \pm 0.75^{\mathrm{a}}$ & $67.30 \pm 0.69^{a}$ & $70.77 \pm 0.89^{b}$ & $<0.001$ \\
\hline MaxL & $44.56 \pm 0.47$ & $44.98 \pm 0.55$ & $46.16 \pm 0.43$ & 0.061 \\
\hline MandRL & $36.10 \pm 0.57^{\mathrm{a}}$ & $37.22 \pm 0.67^{b}$ & $41.50 \pm 0.64^{c}$ & $<0.001$ \\
\hline MandCL & $69.11 \pm 0.67$ & $70.58 \pm 0.50$ & $72.69 \pm 0.56$ & 0.064 \\
\hline OMandL & $96.50 \pm 0.79^{a}$ & $99.52 \pm 0.75^{b}$ & $99.78 \pm 0.83^{b}$ & 0.007 \\
\hline
\end{tabular}

Values are presented as mean \pm standard error.

SS-HD, short-statured children with growth hormone deficiency; SS-I, idiopathic short-statured children; NC, normal children; ACB, anterior cranial base length; PCB, posterior cranial base length; TCB, total cranial base length; UAFH, upper anterior facial height; UPFH, upper posterior facial height; LAFH, lower anterior facial height; ATFH, anterior total facial height; PTFH, posterior total facial height; MaxL, maxillar lenghth; MandRL, mandibular ramus length; MandCL, mandibular corpus length; OMandL, overall mandibular length.

$p$-value of MANOVA, Bonferroni correction $(a<b<c)$.

Table 5. Comparison for the angular craniofacial variables among SS-HD, SS-I, and NC groups

\begin{tabular}{|c|c|c|c|c|}
\hline \multirow{2}{*}{ Angular ( $\left.{ }^{\circ}\right)$} & \multicolumn{3}{|c|}{ Group } & \multirow{2}{*}{$p$-value } \\
\hline & SS-HD $(n=31)$ & SS-I $(n=32)$ & $N C(n=32)$ & \\
\hline SA & $126.92 \pm 0.61^{b}$ & $126.03 \pm 0.43^{\mathrm{ab}}$ & $124.42 \pm 0.56^{a}$ & 0.006 \\
\hline $\mathrm{GA}$ & $127.39 \pm 0.51^{b}$ & $125.38 \pm 0.28^{\mathrm{a}}$ & $124.14 \pm 0.49^{a}$ & $<0.001$ \\
\hline MPA & $36.65 \pm 0.40^{b}$ & $35.83 \pm 0.30^{b}$ & $33.55 \pm 0.51^{\mathrm{a}}$ & $<0.001$ \\
\hline SNA & $79.42 \pm 0.28^{\mathrm{a}}$ & $79.75 \pm 0.35^{\mathrm{ab}}$ & $80.58 \pm 0.26^{b}$ & 0.022 \\
\hline SNB & $75.03 \pm 0.42^{\mathrm{a}}$ & $76.47 \pm 0.36^{b}$ & $78.38 \pm 0.29^{c}$ & $<0.001$ \\
\hline ANB & $4.39 \pm 0.17^{c}$ & $3.28 \pm 0.13^{b}$ & $2.22 \pm 0.13^{\mathrm{a}}$ & $<0.001$ \\
\hline PPMand & $87.19 \pm 0.51$ & $86.16 \pm 0.34$ & $86.45 \pm 0.38$ & 0.201 \\
\hline
\end{tabular}

Values are presented as mean \pm standard error.

SS-HD, short-statured children with growth hormone deficiency; SS-I, idiopathic short-statured children; NC, normal children; SA, saddle angle; GA, gonial angle; MPA, mandibular plane angle; SNA, position of maxilla; SNB, position of mandible; ANB, maxilla versus mandible; PPMand, posterior position of mandible.

$p$-value of MANOVA, Bonferroni correction $(\mathrm{a}<\mathrm{b}<\mathrm{c})$.

and $76.47 \pm 0.36$, and maxilla versus mandible (ANB) were $4.39 \pm 0.17$ and $3.28 \pm 0.13$, respectively, all of which had statistical significance $(p<0.05)$. Significant differences between the SS-HD and NC groups were apparent at saddle angle (SA), GA, mandibu- lar plane angle (MPA), position of maxilla (SNA), SNB, and ANB $(p<0.05)$. Significant differences between the SS-I and NC groups were apparent at MPA, SNB, and ANB $(p<0.05)$. 


\section{Discussion}

Mechanisms that regulate the growth and development of craniofacial regions are expressed by the complex interaction of genes, hormones, nutrition, and epigenetic factors. Interference with these mechanisms can cause changes in growth patterns $[16,17]$.

The relationship between the development of the craniofacial structures and body structures has been shown in various growth studies [18-20]. The study by Chung et al. [21] reported that growth retardation in short stature children affected not only their height but also their craniofacial growth.

In this study, we classified short-statured children into two groups, growth hormone deficient or idiopathic, and compared the characteristics of their craniofacial growth with NC.

This study found that both short-statured children with growth hormone deficiency and idiopathic short-statured children were affected not only in terms of height but also craniofacial growth. Compared to the control group, almost all of the craniofacial structure measurements were significantly different. There was a more disproportionate growth of the cranial base, and jaw which resulted in facial retrognathia in the two short-statured groups.

Both short-statured groups had a shorter cranial base length. This was consistent with the results of van Erum et al. [22], but inconsistent with the results of Spiegel et al. [10], Kjellberg et al. [13], and Poole et al. [23].

The PTFH, MandRL, and OMandL values of the two short-statured groups were higher than the control group. This could be seen in the small mandible and reduced posterior facial height, which might cause the mandible to rotate in short-statured children. Contrastingly, the GA and MPA values of the two short-statured groups were lower than the control group. This could also be seen by the growth pattern of the mandible rotating clockwise in short-statured children. This incongruity of the upper and lower jaws can lead to skeletal malocclusion, thereby requiring orthodontic treatment for tooth occlusion, oral function, and temporomandibular joint issues. The growth pattern of both jaws should also be considered at this time.

There are several limitations to this study. All subjects should be investigated according to sex and age because there are differences between males and females, and the time and amount of growth with age [24]. Besides, the number of participants included in this study was rather small. Therefore, further studies should be conducted with more children that are analyzed according to sex and age, as well as the short stature cause. Despite these limitations, this study is significant in that it identified differences in the development of craniofacial structures in short-statured children.

In conclusion, most of the measurements of craniofacial struc- tures were significantly smaller in both growth hormone-deficient and idiopathic short-statured children. Orthodontic treatment plans should be modified to include these craniofacial structure characteristics.

\section{Acknowledgments}

\section{Conflicts of interest}

No potential conflict of interest relevant to this article was reported.

\section{Author contribution}

Conceptualization, Data curation: all authors; Formal analysis, Methodology: EYP, KBK, EKK; Project administration: EYP, KBK; Investigation: all authors; Resources: EYP, KBK, MSK; Software: EYP, EKK; Supervision: EYP; Validation: EYP, KBK, EKK; Visualization, Writing-original draft, Writing-review \& editing: EYP, KBK.

\section{ORCID}

Ki Bong Kim, https://orcid.org/0000-0002-3974-3050

Eun-Kyong Kim, https://orcid.org/0000-0001-9582-1415

Kyung Mi Jang, https://orcid.org/0000-0002-2226-9268

Min Seon Kim, https://orcid.org/0000-0002-3205-6725

Eun Young Park, https://orcid.org/0000-0002-1860-5425

\section{References}

1. Herpin N. Le pouvoir des grands: de l'influence de la taille des hommes sur leur statut social. Paris: Découverte; 2006.

2. You JB. "My son should be $175 \mathrm{~cm}$ and daughter $165 \mathrm{~cm}$ or more”... Parents worry about discrimination [Internet]. JungAng Ilbo; 2020 Oct 21 [cited 2020 Jun 10]. https://news.joins. com/article/18905427.

3. Barstow C, Rerucha C. Evaluation of short and tall stature in children. Am Fam Physician 2015;92:43-50.

4. Cox LA. The biology of bone maturation and ageing. Acta Paediatr Suppl 1997;423:107-8.

5. Cao F, Huang HK, Pietka E, Gilsanz V. Digital hand atlas and web-based bone age assessment: system design and implementation. Comput Med Imaging Graph 2000;24:297-307.

6. Bilgili Y, Hizel S, Kara SA, Sanli C, Erdal HH, Altinok D. Accuracy of skeletal age assessment in children from birth to 6 years of age with the ultrasonographic version of the Greulich-Pyle atlas. J Ultrasound Med 2003;22:683-90.

7. Lindsay R, Feldkamp M, Harris D, Robertson J, Rallison M. Utah Growth Study: growth standards and the prevalence of 
growth hormone deficiency. J Pediatr 1994;125:29-35.

8. Grote FK, Oostdijk W, De Muinck Keizer-Schrama SM, van Dommelen P, van Buuren S, Dekker FW, et al. The diagnostic work up of growth failure in secondary health care; an evaluation of consensus guidelines. BMC Pediatr 2008;8:21.

9. Lashari SK, Korejo HB, Memon YM. To determine frequency of etiological factors in short statured patients presenting at an endocrine clinic of a tertiary care hospital. PakJ Med Sci 2014; 30:858-61.

10. Spiegel RN, Sather AH, Hayles AB. Cephalometric study of children with various endocrine diseases. Am J Orthod 1971; 59:362-75.

11. Konfino R, Pertzelan A, Laron Z. Cephalometric measurements of familial dwarfism and high plasma immunoreactive growth hormone. Am J Orthod 1975;68:196-201.

12. Cantu G, Buschang PH, Gonzalez JL. Differential growth and maturation in idiopathic growth-hormone-deficient children. Eur J Orthod 1997;19:131-9.

13. Kjellberg H, Beiring M, Albertsson Wikland K. Craniofacial morphology, dental occlusion, tooth eruption, and dental maturity in boys of short stature with or without growth hormone deficiency. Eur J Oral Sci 2000;108:359-67.

14. Partyka M, Dunin-Wilczyńska I, Chałas R. Disorders of the stomatognathic system in patients with short stature. PolMerkur Lekarski 2014;36:63-7.

15. Broadbent BH Sr, Broadbent BH Jr, Golden WH. Bolton standards of dentofacial development growth. St. Louis: CV Mos- by; 1975 .

16. Pirinen S, Majurin A, Lenko HL, Koski K. Craniofacial features in patients with deficient and excessive growth hormone. J Craniofac Genet Dev Biol 1994;14:144-52.

17. Thilander B. Basic mechanisms in craniofacial growth. Acta Odontol Scand 1995;53:144-51.

18. Nanda RS. The rate of growth of several facial components measured from serial cephalometric roentgenograms. Am J Orthod 1955;41:658-73.

19. Björk A, Helm S. Prediction of the age of maximum puberal growth in body height. Angle Orthod 1967;37:134-43.

20. Baughan B, Demirjian A, Levesque GY, Lapalme-Chaput L. The pattern of facial growth before and during puberty, as shown by French-Canadian girls. Ann Hum Biol 1979;6:5976.

21. Chung SH, Kim JW, Park YH, Hwang CJ, Lee HK. The effect of growth hormone treatment on craniofacial growth in short stature children. Korean J Orthod 2010;40:227-38.

22. Van Erum R, Mulier M, Carels C, de Zegher F. Short stature of prenatal origin: craniofacial growth and dental maturation. Eur J Orthod 1998;20:417-25.

23. Poole AE, Greene IM, Buschang PH. The effect of growth hormone therapy on longitudinal growth of the oral facial structures in children. Prog Clin Biol Res 1982;101:499-516.

24. Grimberg A, Kutikov JK, Cucchiara AJ. Sex differences in patients referred for evaluation of poor growth. J Pediatr 2005; 146:212-6. 